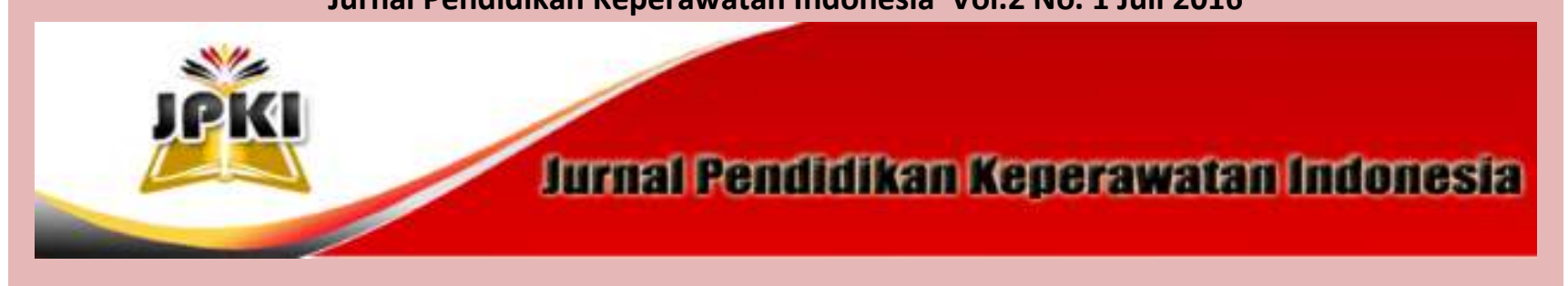

Journal homepage : http://ejournal.upi.edu/index.php/JPKI

\title{
GAMBARAN STIGMA MASYARAKAT TERHADAP KLIEN GANGGUAN JIWA DI RW 09 DESA CILELES SUMEDANG
}

\author{
${ }^{1}$ Gilang Purnama, ${ }^{2}$ Desy Indra Yani, ${ }^{3}$ Titin Sutini \\ ${ }^{1,2,3}$ Fakultas Keperawatan, Universitas Padjadjaran \\ Email : ${ }^{1}$ purnamagilang30@gmail.com
}

\begin{abstract}
ABSTRAK
Stigma merupakan label negatif yang melekat pada tubuh seseorang yang diberikan oleh masyarakat dan dipengaruhi oleh lingkungan. Stigma salah satu faktor penghambat dalam penyembuhan klien gangguan jiwa. Cileles adalah suatu Desa dengan jumlah klien gangguan jiwa yang meningkat setiap tahunnya. Tujuan dari penelitian ini untuk mengetahui gambaran stigma masyarakat terhadap klien gangguan jiwa di RW 09 Desa Cileles. Desain penelitian menggunakan deskriptif kuantitatif. Populasi penelitian 253 Kepala Keluarga dan Sampel 155 responden dengan menggunakan teknik stratified random sampling. Instrumen penelitian menggunakan kuisoner Community Attitudes toward the Mentally Ill dan instrumentnya valid dan reliabel. Analisis data yang digunakan adalah distribusi frekuensi dan skor median. Stigma terdiri dari 4 domain, masing-masing domain skornya $10-50$. Hasil penelitian menunjukan domain otoriterisme mediannya 34 dengan IQR2, selanjutnya adalah komponen berdasarkan domain kebajikan dengan nilai skor 33 dengan IQR 2, kemudian domain ideologi komunitas kesehatan mental dengan skor 33 dengan IQR 4 dan yang paling rendah domain pembatasan sosial dengan nilai 27 dengan IQR 7. Hal tersebut dapat berarti bahwa lebih banyak responden yang menganggap bahwa klien gangguan jiwa harus diperlakukan dengan kasar. Penelitian ini bisa disimpulkan bahwa domain otoriterisme adalah domain stigma yang paling tinggi dan pembatasan sosial adalah domain yang paling rendah. Hasil penelitian ini perlu di tindak lanjuti dengan memberikan intervensi yang tepat sesuai dengan domain-domain yang ada
\end{abstract}

Kata kunci : Gangguan Jiwa, Masyarakat, Stigma.

\section{ABSTRACT}

Stigma is a negative label attached to the body of someone who is paid by the public and influenced by the environment. Stigma one of the inhibiting factor in the healing of clients with mental disorders. Cileles is a village with a number of clients with mental disorders is increasing every year. This research aims to describe the stigma against mental illness clients in $R W 09$ Cileles. This research used descriptive quantitative design. Population consisted of 253 heads of household and involved 155 respondents were taken with stratified random sampling. This research used Community Attitudes toward the Mentally Ill Questionnaire and the instrument was valid and reliable. Data Analyzed with descriptive analysis and used median score. Stigma is composed of four domains, each domain likelihood score is 10-50. Research results from obtained that the median score on the domain of authoritarianism is 34 with IQR 2, next is a component based on the domain of virtue with a score of 33 with IQR 2, then based on the ideological aspect mental health community with a score of 33 with IQR 4 and the lowest is based on aspects of social restrictions with value 27 with IQR 7. This result indicated that majority of respondent considered that patient with mental ill should be treated rudely. To concluded, authoritarianism domain is the highest domain stigma and social restrictions are the domain of the lowest. The results of this study need to be followed up with appropriate interventions in accordance with existing domains.

Keyword: Mental Illness, Society, Stigma 


\section{PENDAHULUAN}

Kesehatan tidak dilihat dari segi fisik saja tetapi dari segi mental juga harus diperhatikan agar tercipta sehat yang holistik. Seseorang yang terganggu dari segi mental dan tidak bisa menggunakan pikirannya secara normal maka bisa dikatakan mengalami gangguan jiwa. Efendi dan Makhfudli (2009) mengatakan gangguan jiwa berat merupakan bentuk gangguan dalam fungsi alam pikiran berupa disorganisasi (kekacauan) dalam isi pikiran yang ditandai antara lain oleh gejala gangguan pemahaman (delusi waham), gangguan persepsi berupa halusinasi atau ilusi, serta dijumpai daya nilai realitas yang terganggu yang ditunjukkan dengan perilakuperilaku aneh (bizzare).

Gangguan jiwa sampai saat ini masih menjadi permasalahan yang serius di dunia. WHO (World Health Organization) (2013) menegaskan jumlah klien gangguan jiwa di dunia mencapai 450 juta orang dan paling tidak ada 1 dari 4 orang di dunia mengalami masalah gangguan jiwa. Di Indonesia jumlah klien gangguan jiwa mencapai 1,7 juta yang artinya 1 sampai 2 orang dari 1.000 penduduk di Indonesia mengalami gangguan jiwa dan di Jawa Barat sendiri klien gangguan jiwa mencapai 465.975 orang serta tiap tahunnya akan terus meningkat (Riskesdas 2013). Banyaknya kasus tentang gangguan jiwa ini bisa menghabiskan biaya pelayanan kesehatan yang besar bagi pemerintah.

Pemerintah dalam menanggulangi gangguan jiwa masih banyak mengalami hambatan. Agusno (2011) mengatakan akar permasalahan pada kesehatan mental berasal dari tiga inti pokok. Pertama adalah pemahaman masyarakat yang kurang mengenai gangguan jiwa, kedua adalah stigma mengenai gangguan jiwa yang berkembang di masyarakat dan terakhir tidak meratanya pelayanan kesehatan mental. Mestdagh dan Hansen (2013) menyatakan masyarakat yang memiliki stigma negatif terhadap klien gangguan jiwa cenderung menghindari dan tidak mau memberikan bantuan terhadap orang yang menderita gangguan jiwa sehingga mempersulit dalam proses penyembuhan.

Stigma dipengaruhi oleh beberapa komponen. Menurut Taylor dan Dear (1981) menjelaskan bahwa ada empat dimensi atau domain stigma gangguan jiwa di masyarakat, yaitu otoriterisme, kebajikan, pembatasan sosial dan ideologi komunitas kesehatan mental. Pengertian stigma sendiri menurut Goffman (2003) merupakan tanda atau tanda yang dibuat pada tubuh seseorang untuk diperlihatkan dan menginformasikan kepada masyarakat bahwa orang-orang yang mempunyai tanda tersebut merupakan seorang budak, kriminal, atau seorang penghianat serta suatu ungkapan atas ketidakwajaran dan keburukan status moral yang dimiliki oleh seseorang. Jadi stigma ini mengacu kepada atribut yang memperburuk citra seseorang.

Stigma yang terus tumbuh di masyarakat dapat merugikan dan memperburuk bagi yang terkena label sosial ini. Girma dkk (2013) mengatakan individu yang terkena stigma di masyarakat sulit untuk berinteraksi sosial bahkan dalam kasus terburuk dapat menyebabkan individu melakukan tindakan bunuh diri. Selain itu penolakan untuk mencari pengobatan, penurunan kualitas hidup, kesempatan kerja yang lebih sedikit, penurunan peluang untuk mendapatkan pemukiman, penurunan kualitas dalam perawatan kesehatan, dan penurunan harga diri (Covarrubias \& Han, 2011). Selain itu penelitian yang dilakukan oleh Mestdagh (2013) stigma tidak hanya berdampak pada klien gangguan jiwa, pada masyarakat yang ada sekitar pun ikut terkena, mereka merasa ketakutan kalau ada klien gangguan jiwa di lingkungan masyarakatnya karena mereka berpikir klien gangguan jiwa suka mengamuk dan mencelakai orang lain. Semua itu merupakan konsekuensi dari stigma gangguan jiwa.

Pemerintah dalam menangani permasalahan stigma ini adalah dengan mengadakan pelayanan, penyuluhan dan penanganan yang terintegrasi berbasis pelayanan kesehatan primer (puskesmas), yang menjangkau seluruh area sampai ke area yang sulit dijangkau. Pemerintah juga mengadakan program pelatihan bagi semua pelayanan kesehatan termasuk kader masyarakat, yang nantinya akan disosialiasikan di masyarakat yang bertujuan meningkatkan pengetahuan masyarakat mengenai gangguan jiwa dan nantinya diharapkan bisa mengurangi akan stigma ini.

Kegiatan Pemerintah untuk mengurangi stigma gangguan jiwa masih tidak 
berjalan dengan lancar. Masyarakat masih banyak yang mendiskriminasi orang yang terkena gangguan jiwa. Hal ini didukung oleh penelitian yang dilakukan Mestdagh (2013) mengatakan masih banyak pasien yang mengalami perlakuan diskriminasi meskipun mereka sudah dalam perawatan kesehatan mental berbasis komunitas. Hal ini ditunjang juga dengan penelitian yang dilakukan Muhlisin (2015) yang mengatakan pasien yang kembali ke masyarakat setelah dinyatakan sembuh tidak mendapatkan dukungan dari rekan-rekan, keluarga dan lingkungan masyarakat, karena mereka beranggapan takut penyakitnya kambuh lagi. Pratiwi dan Nurlaily (2010) menambahkan keluarga yang mempunyai anggota keluarga yang menderita penyakit mental, mereka tidak dilibatkan dalam masalah keluarga, mereka dikurung dan dirantai saat kambuh atau mengamuk.

Penelitian mengenai stigma gangguan jiwa bukan hal yang baru di dalam dunia penelitian Barat. Diantaranya penelitian yang dilakukan oleh Ukpong dan Abasiubong (2010) di Nigeria menemukan bahwa stigma dan diskriminasi sulit dihilangkan, karena masyarakat berkeyakinan bahwa gangguan jiwa disebabkan oleh sesuatu yang mistis. Penelitian lain yang dilakukan oleh Tesfaye dkk (2013) di southwest Ethiopia menemukan bahwa masyarakat pedesaan lebih mudah terpengaruh oleh stigma yang berkembang di masyarakat daripada masyarakat di perkotaan. Di Indonesia sendiri penelitian yang dilakukan oleh Teresha (2015) menyatakan bahwa mahasiswa yang pengetahuannya tinggi tentang gangguan jiwa bisa memberikan sikap yang lebih positif terhadap klien gangguan jiwa. Selain itu review kasus yang dilakukan oleh Syaharia (2008) di Yogyakarta menyatakan pemahaman masyarakat mengenai etiologi gangguan jiwa seringkali dikaitkan oleh nilai tradisi dan budaya serta tidak mau terbuka dengan penjelasan-penjelasan yang lebih ilmiah. Dari sana bisa di ketahui bahwa stigma di pengaruhi oleh beberapa faktor, salah satunya adalah kebudayaan setempat atau lingkungan. Oleh karena itu peneliti merasa perlu melakukan penelitian mengenai stigma masyarakat terhadap gangguan jiwa yang mengambil tempat di Cileles.

Data dari puskesmas Jatinangor Tahun 2014 klien yang menderita gangguan jiwa di
Cileles sebanyak 5 orang. Pada tahun 2015 mengalami kenaikan yaitu menjadi 18 orang dan yang paling banyak berada di RW 09 sebanyak 7 orang (Leli dalam laporan residen, 2015). Ini menunjukan adanya peningkatan jumlah klien gangguan jiwa lebih dari $200 \%$. Hasil studi pendahuluan yang peneliti lakukan kepada masyarakat Cileles, yaitu tiga dari lima orang warga Cileles masih menjauhi klien ataupun keluarga yang memiliki gangguan jiwa, mereka menyatakan tidak ingin terlibat dalam masalah dengan keluarga yang memiliki gangguan jiwa, padahal mereka sangat ingin membantu keluarga dengan klien gangguan jiwa. Masyarakat yang masih takut terhadap klien gangguan jiwa maka akan memperburuk gangguan jiwanya, sehingga proses pemulihan dan rehabilitasi akan terganggu serta akan mempercepat klien untuk kambuh lagi.

Dengan peningkatan jumlah kasus gangguan jiwa yang ada di Cileles dan studi pendahuluan yang peneliti lakukan, klien rentan untuk mendapatkan stigma dari masyarakat sekitar, maka dari itu peneliti tertarik untuk melakukan penelitian mengenai gambaran Stigma Masyarakat terhadap Klien Gangguan Jiwa di RW 09 Desa Cileles Kecamatan Jatinangor Kabupaten Sumedang.

\section{METODE PENELITIAN}

Desain penelitian yang dilakukan dengan metode deskriptif dengan pendekatan kuantitatif. Populasi dalam penelitian ini adalah seluruh Kepala Keluarga di RW 09 Desa Cileles dengan penarikan sampel dalam penelitian ini dilakukan dengan teknik stratified random sampling dan didapatkan sample sebesar $155 \mathrm{KK}$.

Instrumen yang digunakan berupa kuesioner CAMI (Community Attitudes toward the Mentally Ill) dengan jumlah pernyataan sebanyak 40. Instrumen telah diuji dengan uji content validity dan face validity, serta telah dilakukan uji reliabilitas.

Analisa data yang digunakan pada penelitian ini adalah jika data bersitribusi normal maka dianalisa data menggunakan mean dan SD, dan jika data berdistribusi tidak normal maka menggunakan median dan IQR.

Pengumpulan data dilaksanakan pada 26 Mei 2016 sampai 9 Juni 2016 di RW 09 Desa Cileles. 
Purnama, G., Yani, D.I., \& Sutini, T.

\section{HASIL PENELITIAN}

Berdasarkan penelitian didapatkan hasil sebagai berikut :

Tabel 1. Distribusi Frekuensi Karakteristik Responden (n=155)

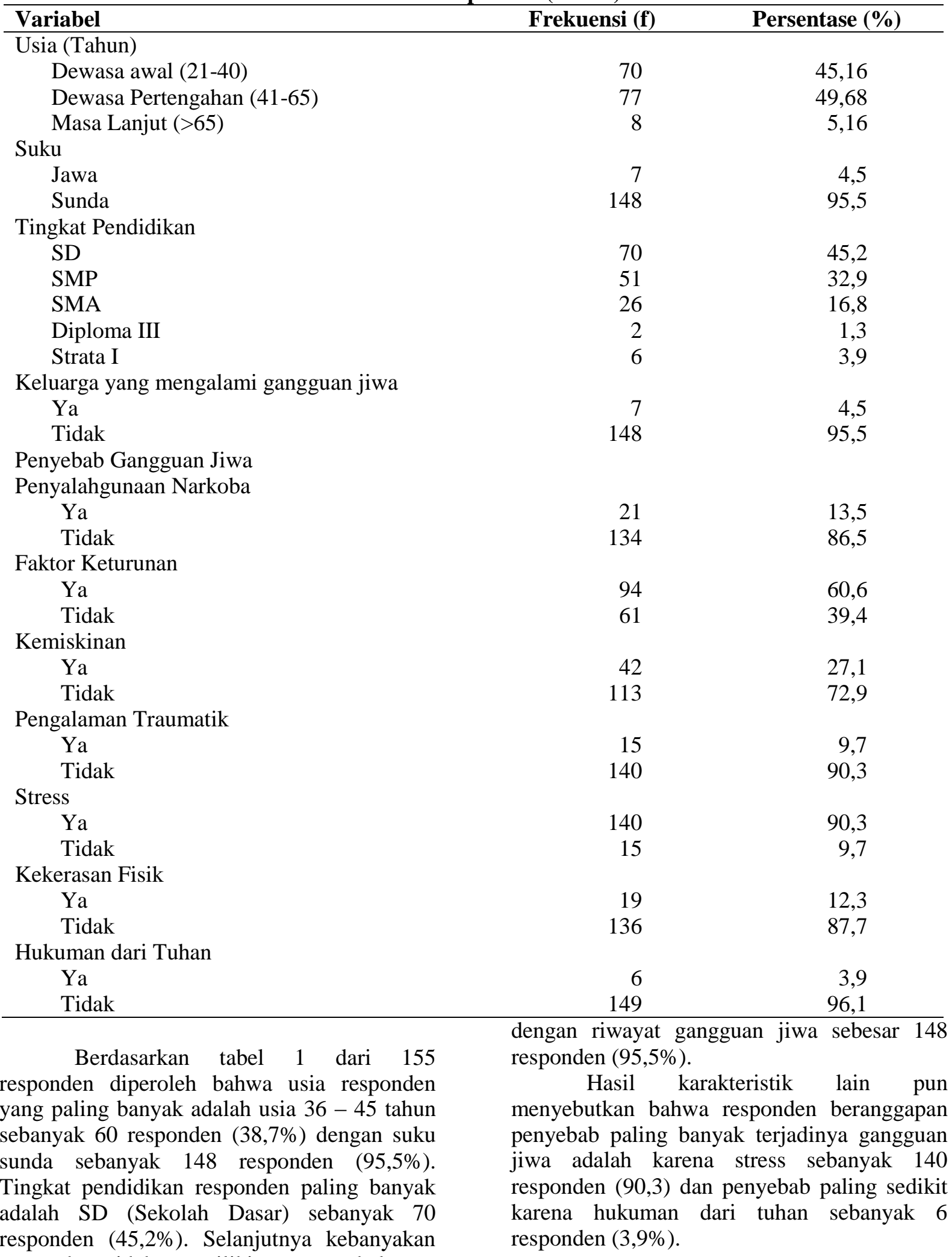


Tabel 2 Distribusi Stigma Masyarakat terhadap Klien Gangguan Jiwa di RW 09 Desa Cileles Kecamatan Jatinangor Kabupaten Sumedang ( $n=155)$

\begin{tabular}{lccccc}
\hline \multicolumn{1}{c}{ Variabel } & $\begin{array}{c}\text { Kemungkinan } \\
\text { Skor }\end{array}$ & Min & \multicolumn{2}{c}{ Maks } & Median IQR \\
\hline Otoriterisme & $10-50$ & 25 & 46 & 34 & 2 \\
Kebajikan & $10-50$ & 24 & 46 & 33 & 2 \\
Pembatasan & $10-50$ & 14 & 39 & 27 & 7 \\
Sosial & & & & & \\
Ideologi & $10-50$ & 25 & 46 & 33 & \\
$\begin{array}{l}\text { Komunitas } \\
\text { Kesehatan }\end{array}$ & & & & & 4 \\
$\begin{array}{l}\text { Mental } \\
\text { Stigma }\end{array}$ & $50-200$ & 109 & 150 & 128 & \\
Gangguan & & & & & 7 \\
Jiwa & & & & & \\
\hline
\end{tabular}

Berdasarkan tabel 2 diatas, didapatkan hasil bahwa nilai median untuk aspek otoriterisme sebesar 34 dengan nilai IQR sebesar 2, dan yang paling rendah untuk aspek pembatasan sosial sebesar 27 dengan nilai IQR sebesar 7. Untuk nilai stigma gangguan jiwa mempunyai nilai median 128 dengan nilai IQR sebesar 7.

\section{PEMBAHASAN}

\section{Gambaran Stigma Masyarakat Terhadap Klien Gangguan Jiwa Di Rw 09 Desa Cileles Kecamatan Jatinangor Kabupaten Sumedang}

Stigma yang melekat pada gangguan jiwa masih menjadi masalah yang jelas. Para ahli kesehatan masyarakat menyatakan bahwa persepsi masyarakat umum mengenai gangguan jiwa sangatlah bermacam-macam, bergantung pada sifat dasar dari gangguan jiwa tersebut. Akibatnya stigma menjadi lebih memberatkan daripada penyakit yang dideritanya dan secara tidak langsung akan memperburuk penyakit gangguan jiwa seseorang.

Stigma gangguan jiwa yang ada di masyarakat dapat diketahui dengan menggunakan instrumen Community Attitude Towards The Mentally Ill yang membagi stigma gangguan jiwa berdasarkan 4 aspek yaitu otoriterisme, kebajikan, pembatasan sosial dan ideologi komunitas kesehatan mental. Instrumen tersebut digunakan dalam penelitian ini. Hasil penelitian diperoleh bahwa aspek Otoriterisme (tabel.4.2) menjadi aspek yang paling tinggi median yaitu sebesar 34 dengan nilai IQR 2. Aspek kebajikan mempunyai nilai median 33 dengan nilai IQR 2, aspek Ideologi Komunitas Kesehatan Mental memiliki nilai median 33 dengan IQR 4 dan yang terakhir aspek yang memiliki nilai median paling rendah adalah aspek pembatasan sosial dengan nilai median 27 dengan IQR sebesar 7.

Otoriterisme yang merupakan pandangan orang terhadap orang dengan gangguan jiwa sebagai seseorang yang lemah dan membutuhkan penangan yang koersif (kasar). Aspek Otoriterisme yang memiliki skor tertinggi adalah Rumah sakit jiwa merupakan upaya yang ketinggalan jaman untuk merawat orang dengan gangguan jiwa yaitu sebesar 4,17 dengan SD 0,925 (Lampiran 5). Dalam penelitian ini bisa dilihat bahwa responden masih meragukan yang dilakukan istansi kesehatan terkait pengobatan klien gangguan jiwa. Hal ini sesuai dengan penelitian yang dilakukan oleh Mesdagh (2013) yang mengatakan bahwa masyarakat tidak percaya bahwa klien gangguan jiwa yang mengalami perawatan kesehatan mental bisa disembuhkan. Selain itu masyarakat meyakini bahwa pengobatan gangguan jiwa pada awalnya diobati dengan cara-cara yang tidak ilmiah, karena gangguan jiwa tersebut dianggap sebagai pengaruh setan atau sikap berontak dari orang yang sakit jiwa (Amir, 2004). Namun sekarang pengobatan berbasis lingkungan sangat dianjurkan dan tidak harus di bawa ke rumah sakit jiwa. Ermalinda (2015) mengatakan bahwa terapi lingkungan sangat dianjurkan untuk klien dengan gangguan jiwa, dikarenakan klien tidak lagi menyendiri, klien dapat berinteraksi dengan keluarga dan lingkungan sekitar, Pengetahuan klien dan keluarga terhadap terapi bertambah, klien lebih terampil kreatifitasnya dan paling penting dapat mencegah kekambuhan gangguan jiwa pada klien. 
Nilai rata-rata skor terendah dalam aspek otoriterisme adalah Cara yang paling tepat untuk merawat orang dengan gangguan jiwa adalah dengan menyembunyikan mereka dalam ruangan yang tertutup sebesar 1,90 dengan SD 0,965 (Lampiran 5). Dalam penelitian ini bisa dilihat bahwa masyarakat di RW09 Desa Cileles tidak mendukung sikap yang harus menyembunyikan klien gangguan jiwa dan hal ini bertentangan dengan penelitian yang dilakukan oleh Pratiwi \& Nurlaily (2010) yang menyebutkan bahwa masyarakat dan keluarga lebih memilih untuk menyembunyikan kondisinya seperti dikurung dan dirantai daripada mencari pertolongan. Dengan demikian masyarakat lebih menerima terhadap klien gangguan jiwa.

Kebajikan merupakan pandangan yang mengacu pada simpati kepada klien gangguan jiwa dan memerlukan pendekatan yang paternal. Aspek Kebajikan yang memiliki skor tertinggi adalah Orang dengan gangguan jiwa layak mendapatkan simpati kita sebesar 4,03 dengan SD 0,789 (Lampiran 5). Pada penelitian ini didapatkan bahwa sebagian besar masyrakat sudah menerima dan membantu klien dengan gangguan jiwa. Hal ini tidak sesuai dengan penelitian yang dilakukan oleh Covarrubias dan Han (2011) menyebutkan bahwa masyarakat sering melakukan penolakan dalam interaksi dengan klien gangguan jiwa karena stigma negatif yang menyertainya serta masyarakat takut bahwa klien gangguan jiwa untuk mengamuk dan mencelakai orang lain (Mestdagh, 2013).

Nilai terendah yang berada pada aspek kebajikan adalah Telah tersedia pelayanan kesehatan jiwa yang cukup untuk orang dengan gangguan jiwa sebesar 2,44 dengan SD 0,891 (Lampiran 5). Dalam hal ini masyarakat tidak setuju dengan pernyataan ini, karena klien dengan gangguan jiwa masih banyak yang tidak tertangani. Pemberiaan pertolongan terhadap klien yang menderita gangguan jiwa harus segera dilakukan agar tidak mempersulit dalam proses penyembuhan (Mestdagh \& Hansen, 2013). Dengan kemajuan pengobatan, banyak klien yang bisa dipulihkan pada fungsi dan tanggung jawab psiko-sosial yang cukup baik (Rahmayulis, 2007).

Ideologi komunitas kesehatan mental merupakan acuan pada penerimaan layanan kesehatan mental dan pasien gangguan jiwa di masyarakat, namun tidak di lingkungan tempat tinggal mereka. Pada aspek ini nilai median yang tertinggi adalah Sejauh mungkin pelayanan kesehatan mental seharusnya disediakan melalui fasilitas berbasis masyarakat sebesar 3,95 dengan SD 0,643 (Lampiran 5). Ini menandakan bahwa masyarakat percaya bahwa fasilitas berbasis komunitas lebih efektif dalam mengobati klien dengan gangguan jiwa. Hal ini di dukung juga dengan penelitian yang dilakukan oleh Hansen (2013) mengatakan bahwa klien dengan gangguan jiwa lebih bisa beraktifitas secara normal jika dilibatkan dalam pekerjaan seharihari di masyarakat seperti bersosialisasi ataupun kerja bakti. Namun hal ini harus dibarengi oleh masyrakat yang pengetahuan nya tinggi mengenai gangguan jiwa agar proses penyembuhan berjalan lancar (Girma, 2013).

Nilai rata-rata terendah dalam aspek Ideologi komunitas kesehatan mental adalah Menempatkan orang dengan gangguan jiwa tinggal di area pemukiman mungkin suatu terapi yang baik, tetapi resikonya terlalu besar sebesar 2,31 dengan SD 0,850 (Lampiran 5). Ini menandakan bahwa masyarakat kebanyakan tidak setuju dengan pernyataan ini dan menandakan bahwa masyarakat tidak khawatir dengan masalah yang ada serta sebelumnya ada sosialisai oleh kader. Penelitian yang dilakukan oleh Teresha (2015) bahwa masyarakat yang pengetahuannya tinggi tentang gangguan jiwa bisa memberikan sikap yang lebih positif terhadap klien gangguan jiwa serta Mestdagh (2013) menyebutkan bahwa perawatan klien gangguan jiwa berbasis masyarakat tidak akan terhambatan, jika masyarakat mau bersosialisasi dengan kilen ganggaun jiwa.

Pembatasan sosial merupakan keyakinan bahwa klien gangguan jiwa merupakan suatu ancaman bagi masyarakat dan harus di hindari. Pada aspek pembatasan 
sosial nilai rata-rata yang tertinggi adalah Kebanyakan wanita yang pernah menjadi pasien di rumah sakit jiwa bisa dipercaya sebagai pengasuh bayi sebesar 3,75 dengan SD 0,809 (Lampiran 5). Ini menandakan bahwa masyarakat meyakini bahwa klien dengan riwayat gangguan jiwa yang telah sembuh masih bisa bekerja dengan semestinya. Gangguan bisa bisa disembuhkan sesuai dengan pernyataan dari Rahmayulis (2007) menyatakan bahwa gangguan jiwa adalah suatu kondisi sakit yang sama seperti penyakit lainnya mempunyai episode kekambuhan dan masa pemulihan. Namun dalam nilai terendah rata-rata adalah Orang dengan gangguan jiwa seharusnya tidak dilanggar hak-hak individunya sebesar 2,25 dengan SD 0,855 (Lampiran 5). Ini menandakan bahwa masyarakat masih berpikiran bahwa hak-hak dari klien gangguan jiwa bisa dilanggar oleh orang lain, seperti hak bersosialisasi dengan lingkungan sekitar ataupun hak untuk mendapatkan pekerjaan. Penelitian yang dilakukan oleh Covarrubias dan Han (2011) menyatakan bahwa klien dengan gangguan jiwa sulit untuk mencari pengobatan, penurunan kualitas hidup, kesempatan kerja yang lebih sedikit, penurunan peluang untuk mendapatkan pemukiman, penurunan kualitas dalam perawatan kesehatan, dan penurunan harga diri.

Nilai total skor stigma gangguan jiwa mempunyai nilai median 128 dengan nilai IQR sebesar 7. Dapat dilihat bahwa stigma masyrakat terhadap klien gangguan jiwa cenderung tinggi ini bisa dihubungkan dengan kebanyka responden berpendidikan terakdir sekolah dasar sehingga pengetahuan akan gangguan jiwa rendah. Saat seseorang mempunyai pengetahuan yang baik tentang gangguan jiwa maka mereka lebih berpikir positif serta stigma negatif akan rendah terhadap klien dengan gangguan jiwa. Namun, jika seseorang pengetahuan tentang gangguan jiwa sedikit maka mereka akan beripikir negatif dan stigma negatif nya tinggi terhadap klien dengan gangguan jiwa. Berbagai aspek domain yang didapatkan dalam penelitian dapat menjadi gambaran stigma masyarakat terhadap klien gangguan jiwa.

\section{SIMPULAN}

Secara umum stigma terhadap klien gangguan jiwa di RW 09 Desa Cileles cenderung meningkat, ditandai dengan nilai total stigma gangguan jiwa mempunyai nilai median sebesar 128 dengan nilai IQR sebesar 7 . Stigma terhadap klien dengan gangguan jiwa dengan median skor teringgi adalah aspek otoriterisme, selanjutnya aspek kebajikan, aspek ideologi komunitas kesehatan mental dan yang terendah adalah pembatasan sosial. Skor Median pada aspek otoriterisme adalah 34 dan IQR 2, selanjutnya adalah komponen berdasarkan aspek kebajikan dengan nilai skor 33, kemudian berdasarkan aspek ideologi komunitas kesehatan mental dengan skor 33 dan yang paling rendah adalah berdasarkan aspek pembatasan sosial dengan nilai 27 .

\section{DAFTAR PUSTAKA}

Agusno, M. (2011). Global - National Mental Health \& Psychosocial Problem \& Mental Health Policy. Yogyakarta: Universitas Gadjah Mada.

Amir, N. (2004). Ilmu Jiwa dalam Tasawuf: Studi Komparatif dengan Ilmu Jiwa. Jakarta: Pustaka Azzam.

Covarrubias, I., and Han, M. (2011). Mental health stigma about serious mental illness among msw students: social contact and attitude: Literatur review. Socia/Work Volume 56, Number 4 October aorr. Di unduh pada tanggal 11 Januari 2016 di http://search.proquest.com/docview/92 2422352/fulltextPDF/BF300E4386374 $\mathrm{C} 26 \mathrm{PQ} / 11$ ? accountid $=48290$.

Depkes RI. 2000. Keperawatan Jiwa Teori dan Tindakan Keperawatan. Jakarta: Balai Pustaka.

Efendi, F., dan Makhfudli. (2009). Keperawatan Kesehatan Komunitas Teori dan Praktik dalam Keperawatan. Jakarta: Salemba Medika. 
Ermelinda., dan Maftuha (2015). Terapi lIngkungan Pada Pasien Gangguan Jiwa. Surabaya: Stikes Abi Surabaya

Foster, M. G., and Anderson, B. G. (2008) Medical Anthropology. New York: John Wiley \& Sons Frank.

Frisch N., \& Frisch A. (2011). Psychiatric mental health nursing. 4 ed. Australia: Delmar CENGAGE learning.Hawari, Dadang.2001. Manajemen Strees, Cemas, dan Depresi. Jakarta : Gaya Baru

Girma, E., Tesfaye, M., Froeschl, G., MollerLeimkuhler, A. M., Muller, N., Dehning, S. (2013). Public stigma against people with mental illness in the gilgel gibe field research center (ggfrc) in southwest ethiopia: Literatur riview. PLoS ONE 8(12): e82116. doi:10.1371/journal.pone.0082116. Di unduh pada tanggal 11 Januari 2016 di http://search.proquest.com/docview/14 64982544/fulltextPDF/BF300E438637 $4 \mathrm{C} 26 \mathrm{PQ} / 9$ ? accountid $=48290$.

Goffman, E. (2003). Stigma: Notes On The Management of Spoiled Identity. New York: Simon\&Schuster Inc.

Hasan, M., dan Iqbal. (2002). Pokok-pokok Materi Metodologi Penelitian dan Aplikasinya. Bogor: Ghalia Indonesia.

Hardy, A. (2005). Trauma and Hallucinatory Experience in Psychosis. Journal of Nervous \& Mental Disease

Hornby, A. S. (2006). The Advanced Learner's Dictionary of Current English, cet III. London: Oxford University.

Jeffrey, S., dkk. (2003). Psikologi Abnormal Edisi V Jilid I. Jakarta: Erlangga.

Kepmenkes Nomor 220/Menkes/SK/III/2002 tentang Pedoman Umum Tim Pembina, Tim Pengarah, Tim Pelaksana Kesehatan Jiwa Masyarakat.

Maramis, W. F, dan Maramis, A. A. (2009). Catatan Ilmu Kedokteran Jiwa Edisi 2. Surabaya: Airlangga University press.

Masyhuri, M. Zainuddin. (2008). Metodologi Penelitian Pendekatan Praktis dan Aplikatif. Bandung: PT. Refika Aditama.
Matsumoto, D. (2004). Pengantar Psikologi Lintas Budaya. Yogyakarta: Pustaka Pelajar.

Mestdagh, A,. and Hansen, B. (2013). Stigma in patients with schizophrenia receiving community mental health care: a review of qualitative studies. Soc Psychiatry Psychiatr Epidemiol (2014) 49:79-87. Di unduh pada tanggal 11 Januari 2016 di http://search.proquest.com/docview/14 73699469/BF300E4386374C26PQ/1? accountid $=48290$.

Muhlisin, A. (2015). Model pelayanan kesehatan berbasis partisipasi masyarakat untuk meningkatkan pelayanan kesehatan jiwa pada masyarakat setempat: Literatur riview. The 2nd University Research Coloquim 2015, 51-57. Di unduh pada tanggal 25 Oktober 2015 di http://jurnal.unimus.ac.id/index.php/ps n12012010/article/viewFile/1568/1620

Noorkasiani,. Heryati,. dan Ismail, R. (2009). Sosiologi Keperawatan. Jakarta: EGC.

Philip, L. H. (2005). Panduan Untuk Memahami Istilah Psikologi. Jakarta: Restu Agung.

Pratiwi, A., dan Nurlaily, F. (2010). Pengalaman Keluarga dalam merawat anggota keluargannya yang mengalami gangguan jiwa di wilayah kabupaten sukoharjo. riset kolaboratif. Jurusan keperawatan. Universitas Muhammadiyah Surakarta. Surakarta.

Republik Indonesia. (2014). Undang-undang Republik Indonesia Nomor 18 Tahun 2014 Tentang Kesehatan Jiwa. Jakarta: Sekretariat Negara.

Riset Kesehatan Dasar. (2013). Pedoman Pewawancara Petugas Pengumpul Data. Jakarta: Badan Litbangkes.

Sarwono, S. W. (2000). Pengaruh Opini Publik terhadap Teori, Diagnosis dan Terapi Gangguan Jiwa. Di unduh pada tanggal 8 Januari 2016 di http://psikologi.ums.ac.id/modules.php ?name $=$ News $\&$ file $=$ article $\&$ sid $=36$ 
Stuart \& Sundeen. (1998). Keperawatan Jiwa Edisi 3. Jakarta: Penerbit Buku Kedokteran EGC.

Sugiyono. (2011). Metode Penelitian Kuantitatif Kualitatif dan R\&D. Bandung: Alfabeta.

Suhaimi. (2015). Gangguan jiwa dalam perspektif kesehatan mental islam: Literatur riview. Jurnal Risalah, Vol. 26, No. 4, 197-205. Di unduh pada tanggal 8 Januari 2016 di http://ejournal.uin-

suska.ac.id/index.php/risalah/article/do wnload/1277/1145.

Suliswati, S. (2005). Konsep Dasar Keperawatan Kesehatan Jiwa Edisi I. Jakarta: EGC

Suryani. (2013). Mengenal gejala dan penyebab gangguan jiwa. Literatur Review Seminar Nasional

Taylor, S. M., \& Dear, M. J. (1981). Scaling community attitudes toward the mentally ill. Schizophrenia Bulletin, 7(2), 225-240. Di unduh pada tanggal 28 Januari 2016 di http://schizophreniabulletin.oxfordjour nals.org/content/7/2/225.full.pdf+html

Teresha, D. A. (2015). Perbedaan pengetahuan, stigma dan sikap antara mahasiswa tingkat awal dan mahasiswa tingkat akhir di fakultas kedokteran universitas jember terhadap psikiatri. Digital Respository Universitas Jember. Di unduh pada tanggal 22 Februari 2016 di http://repository.unej.ac.id/bitstream/h andle/123456789/66769/Dinda\%20Ay u\%20Teresha\%20$\% 20112010101089$.pdf?sequence $=1$

WHO. 2011. Mental Health atlas 2011, Mental Health Organization, ISBN 979924 1564359.

Yosep, I. (2007). Keperawatan Jiwa. Bandung: PT Refika Aditama 